\title{
FAKTOR-FAKTOR YANG MEMPENGARUHI PEMBERIAN PRELAKTAL PADA BAYI BARU LAHIR DI WILAYAH KERJA PUSKESMAS SOKARAJA I
}

\author{
Happy Dwi Aprilina \\ Fakultas IImu Kesehatan, Universitas Muhammadiyah Purwokerto \\ JIn. Soepardjo Rustam KM 7 Purwokerto, Banyumas, Jawa Tengah \\ Email : happydwiaprilina@gmail.com
}

\begin{abstract}
ABSTRAK
Latar belakang: Penyebab dominan kegagalan pemberian ASI eksklusif adalah ibu menganggap bayi menangis disebabkan lapar, sehingga perlu diberikan prelaktal. Prelaktal adalah makanan dan/atau minuman diberikan kepada bayi yang baru lahir sebelum ASI mulai keluar. Data pemberian prelaktal masih dikategorikan tinggi sehingga pemberian ASI Eksklusif belum memenuhi target pemerintah Indonesia. Tujuan Penelitian: mengetahui faktor-faktor yang mempengaruhi pemberian prelaktal pada bayi baru lahir. Metode: Rancangan penelitian menggunakan kasus kontrol (case control) dengan penelusuran retrospektif dengan kelompok kasus $n=33$ dan kelompok kontrol $n=33$. Subjek penelitian yaitu seluruh ibu yang mempunyai bayi umur 1 minggu-1 bulan di wilayah kerja Puskesmas Sokaraja 1, Banyumas. Teknik pengambilan sampel dengan simple random sampling. Variabel yang diteliti adalah usia ibu, kebiasaan prelaktal, pekerjaan, paritas, tingkat pendidikan, dukungan keluarga, dukungan petugas kesehatan dan jenis persalinan. Chi square digunakan untuk analisis statistik. Hasil: Hasil uji chi square pada variabel umur ibu (p:0,63), tingkat pendidikan (p:0,70), pekerjaan (p:0,01), paritas ( $p: 0,27)$, kebiasaan prelaktal ( $p: 0,63)$, dukungan petugas kesehatan ( $p: 0,01)$, dukungan keluarga ( $p: 0,00)$, jenis persalinan ( $p: 0,57)$. Kesimpulan: Variabel yang berhubungan/berpengaruh terhadap pemberian prelaktal pada bayi baru lahir adalah a) ibu bekerja, b) tidak adanya kebiasaan pemberian prelaktal, c) adanya dukungan petugas kesehatan dan d) adanya dukungan keluarga.
\end{abstract}

Kata Kunci: air susu ibu eksklusif; prelaktal; bayi baru lahir.

\begin{abstract}
Background: The dominant cause of failure is the mother of exclusive breastfeeding assume a crying baby due to hunger, so should be given prelacteal. Prelacteal is the food and drink given to newborns before the milk starts out. Data provision prelacteal is still categorized high that exclusive breastfeeding has not met the target of the Indonesian government. Objective: The aim of the study was to determine the factors that influence prelacteal to newborn. Methods: Research design used case-control with retrospective search to the cases $n=33$ and $n=33$ control group with simple random sampling. Research subjects were all mothers who had infants aged 1 week-1 month in Sokaraja District Health Centre 1 , Banyumas. The variables studied were maternal age, habits prelacteal, employment, parity, level of education, family support, health workers support and the type of delivery. Chi square was used for statistical analysis. Results: The chi square test results on the variables of maternal age ( $p$ : 0.63), education level ( $p: 0.70)$, employment ( $p: 0.01)$, parity ( $p$ : $0.27)$, prelactal habits $(p: 0,63)$, the support of health workers ( $p: 0.01)$, family support ( $p: 0.00)$, type of delivery ( $p: 0.57)$. Conclusions: Variables related / influence toward prelacteal feeding to newborn is the mother works, the absence of the habit of giving prelacteal, the support of health workers and the existence of family support.
\end{abstract}

Keywords: exclusive breastfeeding; prelacteal; newborn. 


\section{LATAR BELAKANG}

ASI eksklusif adalah menyusui selama 6 bulan tanpa memberikan makanan atau minuman lain termasuk air putih, susu formula maupun makanan lainnya, kecuali obat-obatan, vitamin ataupun mineral tetes (Riskesdas, 2010). Indonesia telah mencanangkan Peraturan Pemerintah Republik Indonesia Nomor 33 Tahun 2012 tentang pemberian ASI Eksklusif. ASI Eksklusif diberikan pada bayi setelah dilahirkan sampai dengan usia 6 bulan. Setelah usia 6 bulan, bayi mendapatkan Makanan Pendamping ASI (MPASI) dan ASI tetap dilanjutkan hingga berusia 2 tahun (World Health Organization, 2014).

Dinyatakan dalam Riskesdas (2013), pemberian ASI Eksklusif di Indonesia pada bayi usia 6 bulan sebesar $30,2 \%$. Berbeda dengan Dinas Kesehatan Banyumas (2012), pemberian ASI Eksklusif di Kabupaten Banyumas pada bayi $0-6$ bulan sebesar $53.6 \%$, sedangkan di wilayah kerja Kecamatan Sokaraja lebih besar yaitu $53,9 \%$. Menurut Rachmad (2013), persentase tersebut dikategorikan rendah karena pada tahun 2015 target pemberian ASI Eksklusif di Indonesia meningkat sebesar $80 \%$.

Pemberian ASI Eksklusif sering mengalami kegagalan, hal ini disebabkan oleh beberapa faktor. Faktor yang mempengaruhi kegagalan pemberian ASI selama dua bulan yaitu ibu pekerja sebesar $52,6 \%$, persalinan tidak normal sebesar 32,9\%, pendidikan rendah sebesar $28,3 \%$, pengenalan awal bukan ASI (prelaktal) sebesar 42,1\%, mindset/pikiran ibu untuk memberikan bayinya ASI dan susu formula atau makanan pendamping ASI sebesar $52 \%$, paritas $\geq 3$ sebesar $32,2 \%$, keadaan ibu sakit sebesar $32,9 \%$ dan frekuensi ANC kurang lengkap sebesar 10,5\% (Hikmawati, 2008). Menurut Sholichah (2011), penyebab dominan kegagalan menyusui eksklusif adalah ibu menganggap bayi yang menangis disebabkan lapar, jadi perlu diberikan makanan tambahan/prelaktal.

Prelaktal adalah makanan dan minuman yang diberikan kepada bayi yang baru lahir sebelum ASI mulai keluar (World Health Organization, 2009). Alasan pemberian prelaktal beragam yaitu ASI belum keluar atau ASI keluar sedikit sehingga bayi kelaparan. Alasan lainnya adalah adanya kebiasaan pemberian makanan/minuman selain ASI sebelum ASI keluar. Pemberian prelaktal akan mengakibatkan bayi malas menyusu ibunya sehingga menyebabkan produksi ASI terhambat dan tidak lancar. Selain itu, bayi akan mudah terserang gangguan pencernaan, konstipasi, diare, alergi, infeksi telinga dan gangguan pernapasan, karena bayi belum siap mencerna makanan atau minuman kecuali ASI (Widuri, 2013).

Penelitian Nguyen et al. (2013) menyatakan bahwa ada beberapa faktor penyebab pemberian prelaktal. Faktor pertama, adanya persepsi ibu yang salah tentang pemberian ASI 52,4\%, Faktor kedua, promosi susu formula di fasilitas kesehatan sebesar $46,3 \%$. Faktor ketiga, kurangnya dukungan keluarga saat hamil ataupun saat periode kritis dalam tiga hari pertama sebesar $10,6 \%$. Faktor lainnya adalah kurang pengetahuan ibu tentang ASI, cara menyusui kurang tepat, melahirkan dengan operasi cesar dan episiotomi. Penelitian tersebut didukung oleh Nirmalasari (2008), pemberian prelaktal pada bayi baru lahir dengan alasan bayi menangis dan ASI belum keluar sebesar $35,5 \%$.

Pemberian prelaktal pada bayi baru lahir di Indonesia masih dalam kategori tinggi yaitu sebesar $43,6 \%$, sedangkan data di Jawa Tengah sebesar 43,2\% (Riskesdas, 2013). Berdasarkan hasil survey di wilayah kerja Puskesmas Sokaraja 1 , dengan 15 responden ibu yang mempunyai bayi 1 minggu-1 bulan didapatkan 12 bayi baru lahir $(80 \%)$ diberikan prelaktal. Hal tersebut didukung oleh Rosha \& Utami (2013) yang menyatakan bahwa $44 \%$ bayi diberikan makanan prelaktal di Kelurahan Kebon Kelapa dan Ciwaringin, Kota Bogor Tengah.

Data pemberian prelaktal di atas masih dikategorikan tinggi sehingga pemberian ASI Eksklusif belum memenuhi target pemerintah Indonesia. Oleh karena itu, penulis tertarik untuk meneliti faktor-faktor yang mempengaruhi pemberian prelaktal pada bayi baru lahir di Wilayah Kerja Puskesmas Sokaraja I.

\section{METODE}

Rancangan penelitian menggunakan kasus kontrol (case control) dengan penelusuran retrospektif dengan kelompok kasus $\mathrm{n}=33$ dan kelompok kontrol $n=33$. Subjek penelitian yaitu 
seluruh ibu yang mempunyai bayi umur 1 minggu1 bulan di wilayah kerja Puskesmas Sokaraja 1, Banyumas.

Sampel penelitian sesuai dengan kriteria inklusi yaitu ibu yang mempunyai bayi umur 1 minggu-1 bulan di wilayah kerja Puskesmas Sokaraja 1 Kabupaten Banyumas dan ibu yang bersedia menjadi responden. Kriteria eksklusi dalam penelitian ini adalah 1) ibu tidak ada atau ibu terpisah dari bayi seperti meninggal dunia, ibu dan bayi tidak rawat gabung. 2) Indikasi medis perlu diberikan prelaktal seperti bayi mengalami kelainan metabolisme bawaan (galaktosemia klasik, fenilketonuria), bayi dengan BBLR $(<1500$ gram), bayi lahir $<32$ minggu, bayi yang beresiko hipoglikemia, ibu dengan HIV. 3) Bayi mengalami kesulitan saat menyusu/mengalami cacat bawaan seperti cerebral palsy, sindrom down dan lidah besar.

Variabel yang diteliti dalam penelitian ini adalah usia ibu, kebiasaan prelaktal, pekerjaan, paritas, tingkat pendidikan, dukungan keluarga, dukungan petugas kesehatan dan jenis persalinan. Dalam penelitian ini uji statistik yang digunakan adalah chi square.

\section{HASIL}

\section{Karakteristik Subjek Penelitian}

Tabel 1 menunjukkan bahwa karakteristik responden secara mayoritas untuk setiap item adalah ibu berumur 20-35 tahun sebesar 57 $(86,36 \%)$, tingkat pendidikan rendah maupun tinggi sama besarnya yaitu $33(50 \%)$, ibu tidak bekerja sebesar 58 (87,87\%).

Pada karakteristik responden berdasarkan kebiasaan pemberian prelaktal mayoritas adalah ibu yang tidak mempunyai kebiasaan dalam pemberian prelaktal sebesar 42 $(63,63 \%)$. Berdasarkan dukungan petugas kesehatan mayoritas adalah ibu yang tidak mendapat dukungan dari petugas kesehatan untuk memberikan prelaktal sebesar $58(88,06 \%)$. Berdasarkan dukungan keluarga dalam pemberian prelaktal mayoritas adalah ibu tidak mendapatkan dukungan keluarga sebesar 55 $(83,33 \%)$. Berdasarkan jenis persalinan adalah ibu yang bersalin normal sebesar $45(68,18 \%)$.
Tabel 1 Karakteristik Responden Penelitian

\begin{tabular}{|c|c|c|c|}
\hline No. & Variabel & $\mathrm{N}$ & $\%$ \\
\hline \multirow[t]{3}{*}{1.} & Umur Ibu & & \\
\hline & a. 20-35 tahun & 57 & 86,4 \\
\hline & b. $<20,>35$ & 9 & 13,6 \\
\hline \multirow[t]{3}{*}{2.} & Tingkat Pendidikan & & \\
\hline & a. Pendidikan tinggi & 33 & 50,0 \\
\hline & b. Pendidikan rendah & 33 & 50,0 \\
\hline \multirow[t]{3}{*}{3.} & Pekerjaan & & \\
\hline & a. Bekerja & 8 & 12,1 \\
\hline & b. Tidak bekerja & 58 & 87,9 \\
\hline \multirow[t]{3}{*}{4.} & Paritas & & \\
\hline & a. Primipara & 33 & 50,0 \\
\hline & b. Multipara & 33 & 50,0 \\
\hline \multirow[t]{3}{*}{5.} & Kebiasaan Prelaktal & & \\
\hline & a. Tidak ada kebiasaan & 42 & 63,6 \\
\hline & b. Ada kebiasaan & 24 & 36,4 \\
\hline \multirow[t]{3}{*}{6.} & $\begin{array}{ll}\text { Dukungan } & \text { Petugas } \\
\text { Kesehatan } & \end{array}$ & & \\
\hline & a. Mendukung & 58 & 87,9 \\
\hline & b. Tidak mendukung & 8 & 12,1 \\
\hline \multirow[t]{3}{*}{7.} & Dukungan Keluarga & & \\
\hline & a. Mendukung & 54 & 83,3 \\
\hline & b. Tidak mendukung & 12 & 16,7 \\
\hline \multirow[t]{3}{*}{8.} & Jenis Persalinan & & \\
\hline & a. Normal & 45 & 68,2 \\
\hline & b. Tidak normal & 21 & 31,8 \\
\hline
\end{tabular}

\section{Hasil Analisa Bivariat}

Tabel 2 pada variabel umur ibu, hasil uji chi square didapatkan nilai $p=0,63(p>0,05)$, artinya tidak terdapat hubungan antara umur ibu terhadap pemberian prelaktal. Pada variabel tingkat pendidikan, hasil uji chi square didapatkan nilai $p=0,70 \quad(p>0,05)$, artinya tidak terdapat hubungan antara tingkat pendidikan terhadap pemberian prelaktal. Pada variabel pekerjaan, hasil uji chi square didapatkan nilai $p=0,01$ $(p<0,05)$, artinya terdapat hubungan antara pekerjaan ibu terhadap pemberian prelaktal. Pada variabel paritas, hasil uji chi square didapatkan nilai $p=0,27 \quad(p>0,05)$, artinya tidak terdapat hubungan antara paritas terhadap pemberian prelaktal.

Pada variabel kebiasaan prelaktal, hasil uji chi square didapatkan nilai $p=0,00 \quad(p<0,05)$, artinya terdapat hubungan antara kebiasaan prelaktal terhadap pemberian prelaktal. Pada variabel dukungan petugas kesehatan, hasil uji chi square didapatkan nilai $p=0,01 \quad(p<0,05)$, artinya terdapat hubungan antara dukungan petugas kesehatan terhadap pemberian prelaktal. Pada variabel dukungan keluarga, hasil uji chi 
square didapatkan nilai $p=0,00(p<0,05)$, artinya terdapat hubungan antara dukungan keluarga terhadap pemberian prelaktal. Pada variabel jenis persalinan, hasil uji chi square didapatkan nilai $p=0,57(p>0,05)$, artinya tidak terdapat hubungan antara jenis persalinan terhadap pemberian prelaktal. Pada hasil tabel 2 tersebut dapat disimpulkan bahwa variabel yang mempunyai hubungan secara signifikan terhadap pemberian prelaktal bayi baru lahir adalah pekerjaan, kebiasaan prelaktal, dukungan petugas kesehatan dan dukungan keluarga. Pada variabel tersebut akan dianalisa lebih lanjut dengan menggunakan regresi logistik sehingga dapat diketahui varibel yang signifikan secara statistik maupun klinis.

Tabel 2. Hasil analisa bivariat

\begin{tabular}{|c|c|c|c|c|c|c|}
\hline No & Variabel & $\begin{array}{c}\text { Tidak } \\
\text { memberikan }\end{array}$ & Memberikan & $\begin{array}{l}\% \text { Tidak } \\
\text { memberi }\end{array}$ & OR (95\% Cl) & $P$ \\
\hline 1. & $\begin{array}{l}\text { Umur lbu } \\
\text { a. } 20-35 \text { tahun } \\
\text { b. } \quad<20,>35\end{array}$ & $\begin{array}{c}28 \\
5\end{array}$ & $\begin{array}{c}26 \\
7\end{array}$ & $\begin{array}{l}84,84 \\
15,16\end{array}$ & $\begin{array}{c}0,99(0,53-1,86) \\
1\end{array}$ & 0,63 \\
\hline 2. & 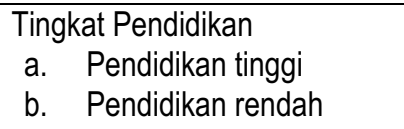 & $\begin{array}{l}16 \\
17\end{array}$ & $\begin{array}{l}19 \\
14\end{array}$ & $\begin{array}{l}48,49 \\
51,51\end{array}$ & $\begin{array}{c}0,92(0,59-1,41) \\
1\end{array}$ & 0,70 \\
\hline 3. & $\begin{array}{l}\text { Pekerjaan } \\
\text { a. } \\
\text { b. } \\
\text { b. Tidak bekerja }\end{array}$ & $\begin{array}{c}1 \\
32\end{array}$ & $\begin{array}{c}9 \\
24\end{array}$ & $\begin{array}{c}3,04 \\
96,96\end{array}$ & $\begin{array}{c}0,20(0,03-1,29) \\
1\end{array}$ & 0,01 \\
\hline 4. & $\begin{array}{ll}\text { Paritas } \\
\text { a. } & \text { Primipara } \\
\text { b. } & \text { Multipara }\end{array}$ & $\begin{array}{l}19 \\
14\end{array}$ & $\begin{array}{l}14 \\
19\end{array}$ & $\begin{array}{l}57,57 \\
42,43\end{array}$ & $\begin{array}{c}1,27(0,82-1,97) \\
1\end{array}$ & 0,27 \\
\hline 5. & $\begin{array}{l}\text { Kebiasaan Prelaktal } \\
\text { a. Tidak ada kebiasaan } \\
\text { b. Ada kebiasaan }\end{array}$ & $\begin{array}{c}28 \\
5\end{array}$ & $\begin{array}{l}14 \\
19\end{array}$ & $\begin{array}{l}84,84 \\
15,16\end{array}$ & $\begin{array}{c}2,39(1,24-4,59) \\
1\end{array}$ & 0,00 \\
\hline 6. & $\begin{array}{l}\text { Dukungan Petugas Kesehatan } \\
\text { a. Mendukung } \\
\text { b. Tidak mendukung }\end{array}$ & $\begin{array}{c}32 \\
1\end{array}$ & $\begin{array}{c}25 \\
8\end{array}$ & $\begin{array}{c}96,96 \\
3,04\end{array}$ & $\begin{array}{c}4,88(0,77- \\
30,88) \\
1\end{array}$ & 0,01 \\
\hline 7. & $\begin{array}{l}\text { Dukungan Keluarga } \\
\text { a. Mendukung } \\
\text { b. } \\
\text { Tidak mendukung }\end{array}$ & $\begin{array}{c}31 \\
2\end{array}$ & $\begin{array}{l}22 \\
11\end{array}$ & $\begin{array}{c}93,93 \\
6,07\end{array}$ & $\begin{array}{c}3,81(1,06- \\
13,74) \\
1\end{array}$ & 0,00 \\
\hline 8. & $\begin{array}{ll}\text { Jenis } & \text { Persalinan } \\
\text { a. } & \text { Normal } \\
\text { b. } & \text { Tidak normal }\end{array}$ & $\begin{array}{c}28 \\
5\end{array}$ & $\begin{array}{l}18 \\
15\end{array}$ & $\begin{array}{l}84,84 \\
15,16\end{array}$ & $\begin{array}{c}0,99(0,53-1,86) \\
1\end{array}$ & 0,63 \\
\hline
\end{tabular}

\section{PEMBAHASAN}

Variabel yang mempunyai hubungan bermakna secara klinis terhadap pemberian prelaktal bayi baru lahir adalah kebiasaan prelaktal, dukungan petugas kesehatan dan dukungan keluarga.

\section{Hubungan Pekerjaan terhadap Pemberian Prelaktal Bayi Baru Lahir}

Berdasarkan hasil analisis diperoleh bahwa ibu yang bekerja 0,20 kali berpeluang untuk tidak memberikan prelaktal bayi baru lahir dibandingkan dengan ibu yang tidak bekerja. lbu bekerja merupakan alasan yang sering dikemukakan oleh ibu yang tidak menyusui bayinya. Alasan ibu bekerja tidak memberikan ASI Eksklusif diantaranya adalah harus meninggalkan bayi di waktu yang lama, waktu cuti yang pendek, mobilitas tinggi sehingga menyulitkan untuk proses menyusui, jarak antara rumah dan kantor jauh serta seringnya ibu untuk dinas keluar kota. Alasan-alasan tersebut memperkuat ibu bekerja untuk melatih 
memberikan makanan/minuman selain ASI agar bayi terlatih saat ditinggal ibu bekerja. Selain itu, kegagalan pemberian ASI Eksklusif di kalangan ibu bekerja biasanya disebabkan karena kurangnya ilmu, informasi dan ketidaktahuan ibu dalam menjalankan ASI Eksklusif tersebut (Azisya, 2010).

Pernyataan di atas sesuai dengan teori Pender et al (2002) dalam Tomey (2006), menyatakan bahwa pengaruh situasional dapat menambah atau mengurangi keinginan untuk berpartisipasi dalam perilaku promosi kesehatan. Pengaruh situasional pada lingkungan eksternal antara lain ibu bekerja yang tidak mendapatkan dukungan dari atasan atau kantor. Selain itu, jika ibu tidak dapat membagi waktu dengan baik antara bekerja dan menjadi seorang ibu akan menimbulkan dampak negatif pada bayinya. Dampak negatif yang ditimbulkan yaitu ibu dengan mudah akan mengambil keputusan untuk memberikan makanan/minuman selain ASI pada bayi. Ibu memberikan makanan/minuman selain ASI dengan alasan ASI tidak keluar dan ibu tidak ada waktu untuk menampung ASI.

Analisis di atas didukung oleh Hikmawati (2008) yang menyatakan bahwa ibu bekerja merupakan faktor resiko terjadinya kegagalan pemberian ASI selama 2 bulan (OR=3,31; 95\% $\mathrm{Cl}: 1,69-6,43)$. Hal ini tidak sesuai dengan penelitian yang dilakukan di Nepal oleh Khanal et al. (2013) yang menyatakan bahwa ibu tidak bekerja lebih banyak memberikan prelaktal pada bayi baru lahir daripada ibu bekerja. Perbedaan pada penelitian ini kemungkinan bisa terjadi dikarenakan adat istiadat, sosial dan budaya yang berbeda.

Menurut Widuri (2013) sosialisasi mengenai hak ibu bekerja untuk dapat memberikan ASI semakin gencar. Bahkan pemerintah sudah membuat peraturan tentang peningkatan pemberian air susu ibu selama waktu kerja di tempat kerja oleh Menteri Negara Pemberdayaan Perempuan, Menteri Tenaga Kerja dan Transmigrasi dan Menteri Kesehatan pada tahun 2008.

Ibu bekerja dapat memberikan ASI Eksklusif dengan pengetahuan yang benar tentang menyusui, perlengkapan memerah ASI dan dukungan lingkungan kerja. Tempat bekerja yang mempekerjakan perempuan hendaknya memilik tempat penitipan anak/bayi. Namun, bila tidak memungkinkan ibu harus memerah ASI secara rutin saat bekerja. Sebelum ibu mengakhiri masa cutinya, ibu harus mulai melatih bayi memberikan ASI perah dengan sendok. Latihan perlu dilakukan agar pengasuh dan bayi mulai adaptasi dalam pemberian ASI perah (Roesli, 2005).

\section{Hubungan Kebiasaan Prelaktal terhadap Pemberian Prelaktal Bayi Baru Lahir}

Analisis menunjukkan bahwa tidak adanya kebiasaan pemberian prelaktal 2,39 kali lebih besar kemungkinan untuk tidak memberikan prelaktal bayi baru lahir dibandingkan dengan adanya kebiasaan pemberian prelaktal. Berdasarkan hasil penelitian ini, kebiasaan pemberian makanan atau minuman selain ASI di wilayah kerja Puskesmas Sokaraja I ditemukan beberapa jenis yaitu susu formula $(67,86 \%)$, madu $(14,29 \%)$, pisang $(10,71 \%)$, air tajin $(3,57 \%)$ dan bubur $(3,57 \%)$.

Kebiasaan atau kepercayaan pemberian prelaktal di masyarakat sudah dilakukan turun temurun dari nenek moyang. Menyusui merupakan kebiasaan turun temurun selama ribuan tahun, namun pemberian ASI Eksklusif masih belum berkembang lama. Orang tua di sekitar ibu menyusui terkadang merasa mempunyai banyak pengalaman dalam merawat dan mengasuh anak. Sering kali kurang orang tua kurang berkenan dengan pemberian ASI Eksklusif.

Pada jaman dahulu bayi baru lahir diberikan makanan seperti pisang yang dihaluskan, madu, bubur dan lain-lain. Alasan pemberian makanan tersebut agar bibir bayi bisa merah dan agar bayi lebih kenyang sehingga bayi tidak rewel. Pengetahuan ibu yang kurang tentang ASI Eksklusif akan menyebabkan ibu percaya dengan adanya kebiasaan pemberian prelaktal tersebut. Selain itu, ibu juga akan merasa takut jika terjadi sesuatu pada bayinya apabila tidak melakukan kebiasaan yang sudah dilakukan dari dahulu (Riksani, 2012).

Penelitian tersebut sesuai dengan Wulandari (2011) yang menyatakan bahwa 
terdapat hubungan antara tradisi ibu dengan pemberian makanan prelaktal pada bayi baru lahir di Desa Supat Timur Kabupaten Musi Banyuasin Sumatera Selatan. Pemberian makanan prelaktal paling banyak dilakukan oleh ibu yang mempunyai tradisi dalam memberikan makanan prelaktal $(87,9 \%)$. Penelitian kualitatif yang dilakukan oleh Kholifah (2008) di Desa Cipicung Kabupaten Padeglang, menyatakan bahwa responden memberikan madu pada bayi baru lahir dengan alasan kebiasaan yang dianjurkan oleh orang tua ketika ASI belum keluar atau keluar hanya sedikit. Pemberian madu dipercayai dapat mengeluarkan kotoran dari dalam tubuh bayi dan dapat membuat bibir bayi menjadi merah.

\section{Hubungan Dukungan Petugas Kesehatan terhadap Pemberian Prelaktal Bayi Baru Lahir}

Analisis menunjukkan bahwa adanya dukungan petugas kesehatan berpeluang 4,88 kali lebih besar untuk tidak memberikan prelaktal bayi baru lahir dibandingkan dengan tidak adanya dukungan petugas kesehatan. Pada penelitian ini, ibu yang mendapatkan dukungan petugas kesehatan untuk memberikan prelaktal sebesar 8 ibu. Petugas kesehatan di wilayah kerja Puskesmas Sokaraja I yang memberikan prelaktal pada bayi baru lahir dikarenakan adanya indikasi medis seperti ibu dan bayi tidak rawat gabung dan bayi hipoglikemia.

Menurut teori Pender et al (2002) dalam Tomey (2006), pemberi pelayanan kesehatan merupakan sumber interpersonal yang penting, sangat mempengaruhi, menambah atau mengurangi keinginan untuk berperilaku promosi kesehatan. Petugas kesehatan merupakan seseorang yang paling dipercaya oleh pasien dan keluarga dalam perawatan pasien. Petugas kesehatan harus mempunyai ilmu yang terbaru dan terpercaya sehingga dapat memberikan perawatan pasien dengan baik. Kepercayaan ibu terhadap petugas kesehatan menjadikan saran dari petugas kesehatan adalah hal yang perlu dan penting dilakukan. Jika ibu diberikan saran untuk memberikan makanan/minuman selain ASI, maka ibu juga akan memberikan kepada bayinya. Ibu akan memberikan makanan/minuman selain ASI tersebut dikarenakan ibu percaya dengan saran petugas kesehatan. Beberapa petugas kesehatan di Indonesia terkadang masih memberikan susu formula kepada bayi baru lahir. Pemberian susu formula tersebut terkadang atas persetujuan ibu atau tanpa persetujuan ibu. Hal tersebut menimbulkan adanya dugaan bahwa banyak petugas kesehatan yang dimanfaatkan oleh produsen susu formula untuk meningkatkan penjualan (Riksani, 2012).

Penelitian tersebut didukung oleh Wulandari (2011), menyatakan bahwa ibu yang mendapatkan dukungan petugas kesehatan untuk memberikan prelaktal diperoleh sebesar $81,6 \%$. Penelitian tersebut juga didukung oleh Adetunji et al. (2006), yang menyatakan bahwa di RS Nigeria Barat petugas kesehatan memberikan prelaktal pada bayi baru lahir. Sebanyak 35\% responden mendapatkan resep untuk memberikan prelaktal. Resep tersebut biasanya diberikan kepada ibu atau keluarga setelah 2 jam melahirkan.

Hasil penelitian tersebut tidak sesuai dengan penelitian ini. Pada penelitian ini, petugas kesehatan mendukung pemberian ASI Eksklusif dan menganjurkan pada ibu untuk tidak memberikan prelaktal. Perbedaan hasil dan pendapat kemungkinan karena petugas kesehatan sudah mendapatkan informasi yang terbaru tentang pemberian ASI Eksklusif dan bahaya prelaktal, sehingga petugas kesehatan menganjurkan kepada ibu untuk tidak memberikan prelaktal pada bayi baru lahir. Selain itu, adanya peraturan pemerintah tentang pemberian ASI Eksklusif yang telah digencarkan dan harus dilaksanakan oleh pelayanan kesehatan, sehingga petugas kesehatan melaksanakan sesuai dengan peraturan yang telah diberlakukan di Indonesia.

\section{Hubungan Dukungan Keluarga terhadap Pemberian Prelaktal Bayi Baru Lahir}

Analisis ini menunjukkan bahwa adanya dukungan keluarga berpeluang 3,81 kali lebih besar untuk tidak memberikan prelaktal bayi baru lahir dibandingkan dengan tidak adanya dukungan keluarga. 
Menurut teori Pender et al (2002) dalam Tomey (2006), keluarga merupakan sumber interpersonal yang penting, sangat mempengaruhi, menambah atau mengurangi keinginan untuk berperilaku promosi kesehatan. Pentingnya keluarga berperan dalam perilaku promosi kesehatan antar anggota keluarga. Promosi kesehatan perlu diberikan kepada semua anggota keluarga sehingga dapat melakukan perilaku yang positif. Salah satu pemberian prelaktal pada bayi baru lahir adalah keluarga yang tidak memahami pentingnya ASI Eksklusif dan bahaya prelaktal. Alasan lainnya yaitu kebiasaan atau kepercayaan dan mitos yang beredar di masyarakat sehingga keluarga akan memberikan prelaktal. Promosi kesehatan tentang prelaktal pada ibu hamil, suami (keluarga inti) dapat mendukung perilaku yang positif yaitu pengambilan keputusan bersama untuk tidak memberikan prelaktal pada bayi baru lahir.

Pada satu atau dua hari pertama setelah melahirkan, ibu sangat tergantung dengan suami dan keluarganya. Pada fase menerima (taking in) ini ibu berharap semua kebutuhannya dapat dipenuhi orang lain. Ibu memindahkan energi dan perhatiannya kepada anaknya. Pada fase ini ibu memerlukan perlindungan dan perawatan dari orang lain, karena psikologis ibu yang belum stabil (Chapman \& Durham, 2010). Kondisi ibu yang masih lemah dan psikologis yang belum stabil terkadang membuat ibu tidak dapat mengambil sebuah keputusan.

Permasalahan seperti ASI yang keluar sedikit pada awal kelahiran bayi terkadang membuat ibu merasa ragu dengan kecukupan ASInya. Dukungan keluarga pada saat kondisi ibu seperti itu sangat dibutuhkan. Keluarga yang mempunyai pengetahuan yang kurang akan mengambil keputusan untuk memberikan makanan/minuman selain ASI (Widuri, 2013). Hal tersebut didukung oleh Wulandari (2011) yang menyatakan bahwa terdapat hubungan antara dukungan keluarga dengan pemberian makanan prelaktal pada bayi baru lahir di Desa Supat Timur Kabupaten.

\section{KESIMPULAN DAN SARAN}

Variabel yang berhubungan/berpengaruh terhadap pemberian prelaktal pada bayi baru lahir adalah ibu bekerja, tidak adanya kebiasaan pemberian prelaktal, adanya dukungan petugas kesehatan dan adanya dukungan keluarga.

\section{REFERENSI}

Chapman, L. \& Durham, R. (2010) Maternalnewborn nursing : the critical components of nursing care. Philadelphia: F. A. Davis Company

Dinas Kesehatan Banyumas (2012) Profil Kesehatan Kabupaten Banyumas tahun 2012. Banyumas: Dinas Kesehatan Kabupaten Banyumas

Dinas Kesehatan Jateng (2012) Buku profil kesehatan Provinsi Jawa Tengah tahun 2012. Semarang.

Nguyen, P. H., Keithly, S. C., Nguyen, N. T., Nguyen, T. T., Tran, L. M. \& Hajeebhoy, N. (2013) Prelacteal feeding practices in Vietnam: challenges and associated factors. BMC Public Health, 1-11.

Rachmad, E. (2013) Menkes minta Sumut fokus tingkatkan ASI Eksklusif dan penurunan kasus AIDS [Online]. http://beritasore.com/2013/04/29/menkesminta-sumut-fokus-tingkatkan-asi-eksklusifdan-penurunan-kasus-aids/. [Accessed tanggal 28 Oktober 2014, pukul 06.00 WIB.

Riskesdas (2010) Riset Kesehatan Dasar (RISKESDAS 2010). Jakarta: Bhakti Husada.

Riskesdas (2013) Riset Kesehatan Dasar (RISKESDAS 2013). Jakarta: Bhakti Husada.

Roesli, U. (2005) Mengenal ASI Eksklusif. Jakarta: Trubus Agriwidya.

Roesli, U. (2007) Mengenal ASI Eksklusif seri 1. Jakarta: Pustaka Pembangunan Swadaya Nusantara

Sholichah, F. (2011) Studi kualitatif penyebab pemberian ASI Non Eksklusif pada ibu

rumah tangga di Desa Ngemplak Kecamatan Undaan Kabupaten Kudus. Skripsi, Universitas Negeri Semarang. 
Apriliana, Faktor-faktor Yang Mempengaruhi Pemberian Prelaktal Pada Bayi Baru Lahir ....

SJKP, Vol. 6 No. 1, Juni 2019, $42-49$

Tomey, A., M \& Alligood, (2006) Nursing theorists and their work,6th edition. St. Louis, Missouri: C.V. Mosby Company.

World Health Organization (2009) Counselling for maternal and newborn health care : a handbook for building skills.: Department of Making Pregnancy Safer.
World Health Organization (2014) Infant and young child feeding. http://www.who.int/mediacentre/factsheets/fs 342/en/ [Online]. [Accessed tanggal 18 Maret 2014 pukul 17.00 WIB].

World Health Organization/Unicef (2011) Pelatihan konseling menyusui modul 40 jam WHO/UNICEF.

WHO/UNICEF. 